RODOLFO CARLOS BARRA

Pontificia Universidad Católica Argentina, Ciudad de Buenos Aires

Universidad Nacional de La Matanza, Provincia de Buenos Aires

\title{
ÓRGANO, OFICIO, COMPETENCIA Y POTESTAD EN EL ORDENAMIENTO CANÓNICO ${ }^{1}$
}

Sumario: - 1. La Iglesia como ordenamiento. - 2. El ordenamiento jurídico. 3. Organización y órgano. - 4. Órgano y oficio. El cargo. - 5. Munus, ministerio y oficio. -6. Las potestades sacras. -7 . Recapitulación: oficio, potestad, órgano y competencia. 8. Las tres concepciones de oficio en el derecho canónico.

\section{La Iglesia como ordenamiento}

Desde una perspectiva eclesiológica, la Iglesia Cuerpo Místico de Cristo y la Iglesia Asamblea del Pueblo de Dios en su peregrinaje temporal, son una misma y única realidad, en indisoluble unidad de naturaleza. Aún así podemos estudiar a aquella "Asamblea" desde un punto de vista jurídico-organizativo, y así afirmar que Jesús de Nazaret y sus apóstoles, fundaron una institución (Hauriou) también un ordenamiento jurídico (Romano, quien reconoció que la teoría del ordenamiento era compatible con la teoría de la institución). Esta institución u ordenamiento se encuentra, desde su fundación, destinada a no perecer, a perdurar en el tiempo para realizar su "idea rectora" o misión salvífica -la salus animarum- en beneficio de todas las generaciones humanas, de todas las tribus, las naciones, las razas, de las gentes de todas las condiciones sociales o económicas, como lo indica el texto paulino (Rom 1, 1:15).

La Iglesia es Pueblo, es decir, un conjunto de personas orgánicamente unidas en la vecindad humana, además de la unión en la corpo-

${ }^{1}$ Conferencia dada en el I Congreso Internacional de Derecho Canónico, UANL-Univ. Panamericana, Mexico DF, enero 2014. 
reidad mística de Cristo, por lo cual es Pueblo de Dios que, con Cristo, expía los pecados en la peregrinación terrena; es comunidad fundada sobre la solidaridad derivada de aquellos vínculos ontológicos, como materia y forma, y sobre la existencia de medios (sacramentos, liturgia) y fines (la santificación) comunes -como también de obligaciones sustancialmente comunes (p. ej., el apostolado, cc. 221 y 216 ) aunque exigibles según el estado y condición de cada uno.

Es útil reiterar aquí lo que recientemente nos ha recordado el Papa Francisco en la Exhortación Apostólica Evangelii Gaudium. La Iglesia es "sujeto de la evangelización", pero como tal "es más que una institución orgánica y jerárquica, porque es ante todo un pueblo que peregrina hacia Dios...lo cual siempre trasciende toda necesaria expresión institucional" (EA, 111).

Aquella nota esencial de la naturaleza de la Iglesia no puede ni debe desplazar a su "necesaria expresión institucional", como vimos que lo advirtió Francisco. La Iglesia es sociedad, ya que se configura como una organización unitaria, corporativa, orgánicamente estructurada. Por ello la Iglesia es institución, sin duda en su peregrinaje temporal y, quizás también, en su realidad meta-histórica, como comunidad de los santos. En Ella, que en este mundo actúa como sociedad (es decir, institución u ordenamiento), "subsiste en la Iglesia católica, gobernada por el sucesor de Pedro y por los Obispos en comunión con él”, tal como lo afirma el c. 204 \&2 siguiendo a la Lumen Gentium. La institución perdura en unidad de esencia (subsiste) en la Iglesia-Cuerpo místico, pero también Pueblo, que requiere del gobierno de sus Pastores, todos, en "comunión misionera", como también lo señala la EG, en el $\mathrm{n}^{\circ} 23$, con cita de Juan Pablo II.

\section{El ordenamiento jurídico}

Enseñaba Santi Romano que toda institución es un ordenamiento jurídico. Pero todo ordenamiento supone, y exige, una determinada organización. En realidad, la organización, cuando no se trata de un mero orden estático de cosas o personas yuxtapuestas, sino un orden dinámico destinado a realizar una determinada finalidad interna o externa, es 
la base fundacional del ordenamiento jurídico, su "primer momento", aunque en un "segundo momento" se convierta en un elemento indispensable del mismo ordenamiento (claro está que estas distinciones temporales son meramente ideales; normalmente con la organización nace el ordenamiento). Es así que el ordenamiento jurídico es un sistema cuyos elementos principales son la autoridad, la organización, los sujetos, las relaciones jurídicas y las normas, amén de la idea rectora que le sirve de causa final, en el sentido tomista del término.

Cuando los sujetos integrantes del ordenamiento son complejos, es decir un conjunto de personas físicas, dan vida, a la vez, a ordenamientos jurídicos menores existentes dentro del ordenamiento mayor, normalmente dotados de personalidad jurídica propia. Es lo que Romano denominaba como "pluralismo ordinamental", esencial para el dinamismo del propio ordenamiento mayor, el que integra a todos en una última organización común. Por ello es muy importante la estructuración de relaciones entre el ordenamiento mayor y los ordenamientos menores, donde debe aplicarse la que sin duda es la principal regla de organización social, la subsidiariedad.

Desde la paz de Westfalia hasta la actualidad los ordenamientos jurídicos mayores o "integrativos" (los menores son los "integrados") son los Estados nacionales. No existe, en sentido estricto, un ordenamiento jurídico internacional porque no existe (todavía) una autoridad común y consentida que, de manera participativa y subsidiaria, conduzca la acción del ordenamiento hacia el bien común y, también para ello, resuelva los conflictos que podrían plantearse dentro de los ordenamientos menores (los Estados nacionales), tal como lo propusieron Juan XXIII en la encíclica Pacem in terris y Benedicto XVI en la Caritas in veritate.

La Iglesia es ordenamiento jurídico porque se estructura conforme a los elementos que hemos visto antes: los sujetos, sus relaciones jurídicas, las normas, la autoridad y sus relaciones con los restantes sujetos, y la idea rectora, que en este caso es la salus animarum, en definitiva, la suprema ley del ordenamiento, además de la organización, 
que es la que permite cumplir con dicha regla y finalidad esencial del ordenamiento eclesiástico.

\section{Organización y órgano}

Si el ordenamiento es organización, la funcionalidad del mismo para la obtención de sus fines, exige la actuación de la organización hacia el interior y hacia el exterior de la misma. Hacia el interior porque siendo la organización, por definición, compleja, requiere de la coordinación y colaboración de sus distintos componentes, con la indispensable aplicación del principio de jerarquía. Hacia el exterior ya que, salvo excepciones, las organizaciones tienen fines, tanto los principales como los secundiarios e instrumentales, que las trascienden: en el caso del ordenamiento de la Iglesia, la salvación de todos y cada uno de los hombres.

La organización no puede actuar por sí sola, ya que en sí misma es un conjunto abstracto, un sistema. Así entonces, sería imposible, además de desacertado, estudiar la organización (cualquier organización) sin partir de su concreto y fundamental núcleo de actuación: el órgano, al que podemos identificar como "la síntesis unitaria de la organización": de esta manera el órgano a la vez que nace de la organización, la sintetiza en la actuación de sus competencias. Con esto se quiere indicar que la misma organización genera centros o núcleos de actividad donde se agrupan las potencialidades de aquélla, aptas y destinadas para el cumplimiento de sus objetivos y fines, de acuerdo con las reglas de competencia establecidas por el mismo ordenamiento.

El órgano puede ser analizado desde dos aspectos: uno, subjetivo y estático, relativo a su "titular", que de ninguna manera se confunde con el órgano mismo, lo que nos conduce al instituto de la función personal o del funcionariado, los que sirven al funcionamiento de la organización, cuyo centro son los funcionarios, ya sean políticos o "de línea", con competencia decisoria y burocracia de apoyo, instituto que existe tanto en las organizaciones públicas como privadas. La otra perspectiva es la objetiva y dinámica, que nos conduce hacia el estudio de la producción de la organización, esto es de las conductas, las decisiones 
y sus elementos, sin perjuicio de los fenómenos jurídicos de la atribución orgánica y de la imputabilidad subjetiva. Digamos simplemente que la primera -la atribución- es el fenómeno fundado especialmente en el principio y regulación de la competencia por el que la actuación del órgano se atribuye a la organización (el acto administrativo válido se considera emanado de la organización) mientras que el principio de la imputación supone la adjudicación de las consecuencias jurídicas de la actuación del órgano y de cualquier funcionario a un determinado sujeto jurídico, en la medida que así lo disponga el ordenamiento.

En base a las ideas anteriores podemos ensayar una definición de órgano -más descriptiva que conceptual y pensando especialmente en las organizaciones regidas por el derecho público- según la cual órgano es todo sector de la organización objetivamente identificable, donde, en virtud del instrumento técnico-organizativo y jurídico de la competencia, se sintetizan los elementos que permiten a aquélla (la organización) desarrollar o producir su actuación propia, tanto interna como externa, de manera tal que lo actuado por el órgano, se pueda atribuir a la vez y por igual, tanto al órgano emisor o ejecutor como a la organización de la que éste forma parte consubstancialmente.

Como ya hemos visto, la organización se rige, entre otros, por el principio de la jerarquía. Existe un órgano (o una pluralidad de ellos, como en el sistema constitucional de la división de poderes) que es autoridad, en el sentido que sintetiza el centro de poder del ordenamiento. Para que pueda cumplir con eficiencia y eficacia este rol funcional, la organización-ordenamiento lo dota de la calidad de ser síntesis competencial última y abarcativa de toda la organización, donde se concentran todas las competencias de actuación de la misma. De esta manera, el órgano superior concentra las competencias de todos sus inferiores, salvo que a estos el ordenamiento les haya otorgado, por excepción normalmente fundada en razones funcionales, competencias desconcentradas. Por efectos de la concentración, el órgano superior puede avocarse en las competencias de ejercicio de los órganos con respecto a él inferiores, creados por el ordenamiento para facilitar las actuaciones parciales de la organización. 
El ordenamiento de la Iglesia presenta la particularidad de destacar la figura del oficio sin referirse expresamente a la de órgano. ¿Es sólo una cuestión terminológica?

\section{4. Órgano y oficio. El cargo}

Las nociones de órgano, oficio -y también "munus"- tienen en común el ser "figuras organizativas", es decir elementos creados por el ordenamiento al servicio de la organización según regímenes jurídicos específicos de acuerdo con cada ordenamiento concreto. Lo mismo es predicable con relación a la noción de persona jurídica que, desde el punto de vista de la organización, también se encuentra al servicio de la misma según lo dispuesto por el ordenamiento, aunque específicamente destinada a la dotación de efectos y consecuencias a las relaciones (entre personas físicas, ordenamientos menores, o incluso órganos) que el ordenamiento mayor califica como jurídicas.

En la Edad Media los canonistas tomaron la idea romana de officium como técnica de subjetivación de ciertos cargos eclesiásticos, con la intención de otorgarle continuidad a la gestión de los patrimonios a ellos confiados y también para institucionalizar, en sí mismo, ciertas funciones o cargos unipersonales, como el del Papa y el del Obispo, de existencia necesaria conforme al derecho divino. En el plano secular el "oficio" indicaba a la Corona, personalizada como en Inglaterra, al cual se le someten sus órganos, y de ahí se pasa, en el continente y especialmente luego de la Revolución Francesa, a la personalización del "Estado", que, además de expresar una fuerte impronta ideológica, tiene una trascendencia determinante en lo que respecta a la construcción de una teoría política de la organización social como ordenamiento jurídico mayor.

En orden a comparar la situación y posibilidad de las doctrinas de la organización estatal, conviene que recordemos a Giannini y su distinción entre el "oficio subjetivo" y el "oficio objetivo". El primero se confunde con el "munus", en definitiva un "servidor", un sujeto que recibe por parte del ordenamiento el cometido de atender intereses de otro, y así podría serlo el "representante legal" de las personas jurídicas 
y de los incapaces de hecho. El "oficio objetivo" se diferencia del anterior en cuanto es "titular del interés del ente de pertenencia", de manera que la persona física - podría también ser, para Giannini, jurídica- que es la que ejerce el oficio, se confunde con éste.

Es útil también la idea de oficio en cuanto munus, es decir, en su sentido subjetivo, el que, sobre todo en los ordenamientos civiles, podemos identificar como "cargo", como veremos luego. En cambio al oficio, en su sentido objetivo, y en este caso sólo para los ordenamientos civiles, lo considero semejante a la figura del órgano.

Pero, me permito proponer, esta identificación no es tal en el ordenamiento jurídico de la Iglesia, donde el concepto de oficio adquiere una importancia especial, sobre lo que también volveremos.

Otra figura organizativa de importancia, tanto en el derecho público laico como en el eclesiástico, es la de "cargo", o conjunto de deberes y derechos de la persona física que ejerce legítimamente la titularidad -es decir, tiene el "título" para ello, título que reside en el acto de designación del oficio o del órgano y su toma de posesión formal cuando ello es exigido, ya sean aquellos unipersonales o colegiados.

Mientras que el órgano es un elemento objetivo de la organización -fundamentalmente es sede de la competencia- el "cargo" (también, por implicancia, "categoría" o "nivel"), en cambio, es el estatus jurídico que autoriza a la persona física a ejercer la competencia del órgano y determina las exigencias de su ejercicio es decir, el modo de prestación de la fuerza de trabajo de la persona a cargo, en beneficio del órgano y de la organización. En definitiva, el cargo delimita la situación jurídica del funcionario o jerarca en la organización.

\section{Munus, ministerio y oficio}

En los ordenamientos civiles el órgano es la sede de la competencia, mientras el cargo podría también asimilarse al desempeño del oficio del funcionario, conforme a su cargo. En este sentido se asemeja mucho a la figura del munus.

La idea de "munus" como "cargo", que sugiero como posible en los ordenamientos civiles, no se encuentra totalmente alejada de la que, 
creo, también admite el CIC, aunque aquí tenemos un matiz importante. Así el c. 145 define que "officium ecclesiasticum est quodlibet munus...", lo que ha sido traducido en castellano como "oficio eclesiástico es cualquier cargo...", mientras que en italiano es "L'ufficio eclesiástico é qualunque incarico...". Desde esta perspectiva legislativa, munus, oficio y cargo parecen conceptos, si bien no sinónimos pero sí orientados a expresar realidades convergentes: el munus es un oficio servicial de finalidad espiritual como lo define el c. 145 (solo así pueden concebirse en la Iglesia, por lo cual todo oficio es un munus) que corresponde ejercer a quien se encuentra a cargo del mismo, nota que hace a la validez de la obtención y posesión del oficio y, consecuentemente, de su ejercicio.

A pesar de la comunidad de ideas contenidas en aquellos conceptos, parecería que el término munus quisiera expresar una realidad de carácter sacramental, en línea con el, en definitiva, principio integrador de las potestades sacras, que, en sus distintos ámbitos de especificación -siempre con respecto a las tres potestades sacras- actualizan, ponen en acto, el munus en la vida de la Iglesia-ordenamiento.

Recordemos también que el ordenamiento de la Iglesia utiliza diversas figuras organizativas no plenamente personificadas y complementarias entre sí, como ocurre con las de "munus", "oficio" y "cargo". A estas cabe agregar, si bien en otro plano, como veremos, la de "ministerio".

Estas figuras no son siempre utilizadas en el derecho de las organizaciones públicas civiles de la misma manera que se lo hace en el correspondiente a la organización de la Iglesia, y aún aquí estos términos carecen, es cierto, de un sentido preciso y unívoco. A pesar de ello su análisis resulta de gran importancia para el ordenamiento eclesiástico teniendo en cuenta su incidencia sobre el ejercicio de las denominadas "potestades sacras", aún cuando munus tiene un mayor sentido teológico-eclesial, mientras que la "potestas" tiene un mayor efecto jurídico. Esto es así por su relación con el oficio, que si bien es munus en cuanto participación ontológica y sacramental en los mumera de Cristo, según lo explica la NEP, es también sede de la "potestas" como nota organi- 
zativa del ordenamiento. Mientras que el munus indica o subraya sacramentalidad, el oficio y la potestas indican y subrayan la juridicidad de la organización.

En términos generales las figuras de "munus" y "ministerio" también se integran entre sí. La "munera" es una acción de servicio, de donación hacia otro, eminentemente pastoral, aún en su aspecto jurisdiccional. Los ministerios harían referencia a las acciones pastorales concretas, como el "ministerio de la palabra divina", que corresponde "principalmente al Romano Pontífice y al Colegio Episcopal" (c. 756, \& 1) a cada Obispo en su diócesis (idem, \& 2), a los presbíteros y diáconos (c. 757, cit.), a los "miembros de los institutos de vida consagrada" asistiendo al Obispo diocesano (c. 758) e, indirectamente, a los fieles laicos, que "pueden ser llamados a cooperar con el Obispo y con los presbíteros en el ejercicio del ministerio de la palabra" (c. 760).

Pero aún así no se trata de una complementación o equiparación absoluta, en cuanto el munus, como ya vimos, indicaría siempre el ejercicio servicial de una o del conjunto de las tres potestades sacras integrantes de la "tria munera" sacerdotal de Cristo. Esta plenitud del "munus", sólo corresponde al "orden clerical", mientras que el ejercicio de ciertos y concretos ministerios puede quedar a cargo de laicos, como en el ejemplo anterior del citado c. 760, o también, siempre a título de ejemplo, en el caso de la "sagrada comunión" donde sus ministros ordinarios son el Obispo, el presbítero y el diácono (c. 910, \& 1), mientras que es ministro extraordinario el acólito o, en ciertos casos, cualquier laico aunque no sea acólito, cuando no haya ministros, ni acólitos ni lectores (idem, \& 2; c. 230, \& 3). Notemos que este parágrafo 3 autoriza a cualquier laico, siempre en situaciones excepcionales, a ejercer "el ministerio de la palabra", amén de suministrar los sacramentos del bautismo y de la comunión. Pero esta excepcionalidad encuentra fundamento no sólo en una cuestión de necesidad, sino en una razón eclesiológica más profunda: todos los fieles cristianos, que por ello son miembros del Pueblo de Dios, participan del sacerdocio real de Cristo, tanto los laicos como los clérigos (c. 204.1) estos últimos destinados a los ministerios sagrados (c. 232). 
En el ordenamiento eclesiástico, entonces, los ministerios se manifiestan en actividades concretas, en principio propias del "orden sagrado" - de quienes ejercen el "sacerdocio ministerial" propiamente dicho- y de manera ordinaria pero limitada - caso de los laicos que ejercen los ministerios concretos de lectores y acólitos- o de manera extraordinaria, al resto de los fieles laicos. Es decir, el ministro no es un órgano, ni el ministerio un complejo orgánico, como sí ocurre en los ordenamientos civiles. El ministro es la persona concreta-que, en los supuestos principales habitualmente es quien ejerce un "oficio", el que, por estar reservado al orden clerical, se denomina "oficio eclesiástico" o "clerical" - y el ministerio es también la concreta actividad salvífica o sacramental que practica el ministro.

En un sentido estricto, el ministro es el sacerdote -de allí que este ejerce el "sacerdocio ministerial" - y éste es el que ha recibido el sacramento del "orden sagrado", por el cual se incorpora, desde el punto de vista de la organización, al "orden", “ordo" o estamento sacerdotal o clerical.

El sacramento del "orden sagrado" también confiere a quien lo recibe la calidad o habilidad para ejercer un oficio - aunque hay oficios que pueden ser desempeñados por laicos (c. $228, \&$ 1)- pero aún así no es jurídicamente suficiente para tal fin. Es decir, no basta estar "ordenado" para ejercer un oficio. Para esto es preciso la emisión de un acto jurídico por parte de la autoridad competente, que es llamado, según los casos, "incardinación" o "misión canónica".

Mi opinión es que el oficio es siempre una figura asociada a la potestas y por tanto no es susceptible de ser ejercido por laicos, aunque estos puedan ejercer ministerios concretos, en el sentido ya indicado. Es cierto que la redacción del c. 228.1 podría llevar a una conclusión distinta, pero no debe excluirse una interpretación más estrecha, según la cual son llamados para asistir en los oficios eclesiásticos, como ministros o como órganos, en los casos que desempeñan cargos estructurados en la potestad de régimen como actividad materialmente administrativa, o también en otras actividades de asesoramiento a quien desempeña el oficio. 
El ministerio, en la expresión de Arrieta, es una "posición personal de obligación" o de "deber" por parte de quien lo ejerce, sea sacerdote ordenado o, en un sentido lato e impropio, laico. El ordenado ejerce sus ministerios, pero no necesariamente un "oficio" que es una determinada cualidad jurídica establecida por el ordenamiento para el ejercicio de ciertas actividades ministeriales. Así, ejemplifica Arrieta, el oficio de párroco, cuando es concedido, califica en una específica manera -jurídicamente, agregaríamos nosotros- el ministerio del presbítero. Es decir, el presbítero ejerce el ministerio sacerdotal, mientras que el párroco -que debe ser presbítero- además, lo hace con relación al determinado oficio de tal.

La persona física ordenada es, por la propia virtud del sacramento del orden, sacerdote (ministerial) que ejerce, entonces, determinados ministerios conferidos por el ordenamiento. Puede o no ser titular de un oficio, es decir, de una situación subjetiva vinculada con el ejercicio de las potestades sacras.

La Nota Previa Explicativa (NPE, 2) a la Constitución Dogmática Lumen Gentium aclara esta cuestión al referirse a la consagración episcopal: "En la consagración se da una participación ontológica de los ministerios sagrados... Se emplea intencionalmente el término ministerios y no la palabra potestades, porque esta última palabra podría entenderse como potestad expedita para el ejercicio. Mas para que de hecho se tenga tal potestad expedita, es necesario que se añada la determinación canónica o jurídica por parte de la autoridad jerárquica. Esta determinación de la potestad puede consistir en la concesión de un oficio particular o en la asignación de súbditos, y se confiere de acuerdo con las normas aprobadas por la suprema autoridad. Esta ulterior norma está exigida por la misma naturaleza de la materia, porque se trata de oficios que deben ser ejercidos por muchos sujetos, que cooperan jerárquicamente por voluntad de Cristo".

El estudio de los diferentes conceptos técnico-organizativos que se emplean en el texto trascripto, que haremos a partir de ahora, ayudará a su mejor comprensión. 
Entre estos conceptos técnico-organizativos fundamentales, sin perjuicio de su principal valor como conceptos teológicos, según los casos, se destacan los de "misión canónica", "incardinación", "munus", "oficio", sobre los que iremos profundizando gradualmente, sin perjuicio de lo que ya hemos adelantado hasta ahora.

\section{Las potestades sacras}

En la Iglesia, como en todo ordenamiento jurídico se presenta-con carácter esencial para su misma subsistencia- el elemento poder o autoridad, el que, dentro de la especificidad del ordenamiento eclesiástico, se concreta en tres potestades: la de orden o de santificar, la de magisterio y la de régimen, aunque todas ellas esencialmente vinculadas por la finalidad última común que es la salus animarum. Cada una de estas, desde el punto de vista jurídico, habilita para el ejercicio, aunque no de manera igual en cada caso, de un conjunto de competencias confiadas a oficios y ejercidas, en ciertos casos y en lo que respecta a la potestad de régimen, principalmente en su actividad administrativa, por órganos en la relación funcional prescripta por el mismo ordenamiento.

Debemos preguntarnos acerca de la naturaleza y contenido de una "potestad", como concepto abstracto. La potestad es la cualidad propia del centro de poder del ordenamiento, que se realiza en el ejercicio del gobierno o conducción conforme con la naturaleza del mismo ordenamiento. Así en los ordenamientos estatales la potestad se ejerce a través de las acciones -jurídicamente, de las "funciones"- de administrar, juzgar y legislar bajo el impulso de una determinada concepción de gobierno que se justifica por la necesidad de lograr el bien común: recordemos que el poder es la causa formal de la comunidad política, mientras que el bien común es su causa final, la causa de las causas, como enseñaban Aristóteles y Santo Tomás. Por ende, en el sentido estricto de los términos, hay una sola potestad aunque se exprese jurídicamente en las tres funciones mencionadas. De todas maneras, en tanto que el modo propio de ejercer la potestad -política, en el caso de los ordenamientos estatales-es a través de las funciones, es habitual asimilar ambos términos: potestad (poder) y función que sería así el 
modo constitucional de ejercicio del poder. Este, en el constitucionalismo moderno, aparecerá así separado en tres ramas o sectores, cada uno ejerciendo una función con una actividad jurídica predominante pero no exclusiva.

En el ordenamiento eclesiástico la potestad es de diversa naturaleza, en tanto el fin del mismo es la salvación de las almas, esto es, un fin sobrenatural, aunque deba comenzar a ser transitado ya en el tiempo. Por ello en el ordenamiento estatal el poder y su atributo propio, la potestad, son políticos, e.d., para el gobierno de la polis o comunidad política. En cambio en el ordenamiento eclesiástico el poder y la potestad que le es inherente son sagrados, en cuanto dedicados a unir a las criaturas con el Creador. La potestad en la Iglesia es sacra, porque la misma Iglesia es sacramento que expresa sensible y eficazmente la gracia de Dios para la salud de las almas. Es un poder de conducción pastoral, para "apacentar el Pueblo de Dios", como lo señala el n 18 de la LG.

Por consiguiente, existe una correlación necesaria entre las potestades de "orden", de "magisterio" y de "régimen", sin perjuicio de la distinción que las tres admiten como potencias que se especifican por sus actos y por los objetos propios de tales actos. Esta distinción, de todas maneras, no puede desconocer que las tres potestades encuentran en Cristo su principio de unidad, en tanto que fuente de su esencia y existencia, principio de unidad que ha sido instituido por el mismo Fundador en Pedro y en el Colegio Apostólico con la presencia de Pedro. En este sentido afirma Cardia, que "la estructura eclesiástica es portadora de una dialéctica continua entre experiencia espiritual y organización jurídica", continuidad dialéctica que también debe predicarse con respecto a la relación entre las tres potestades. Estas reflejan también una complementariedad más o menos necesaria según el oficio de que se trate. En el caso del oficio petrino y en el Colegio Episcopal con el Papa, esta complementariedad es absolutamente necesaria, inderogable e indeleble, ya que es de derecho divino. En estos oficios, podría afirmarse, las tres potestades encuentran su punto de unión sustancial.

Precisamente la LG trata de las tres potestades en un mismo Capítulo, el número III; entre los números 18 y 24 desarrolla una introducción 
con referencias especiales a la potestad de orden, en el número 25 expone la potestad de enseñar o de magisterio, mientras que en el 26 hace referencia a la potestad de santificar y en el 27 a la potestad de regir, todo como parte del ministerio sacerdotal, y en particular episcopal.

También Arrieta subraya que el orden sagrado es "un requisito previo y habilitación subjetiva" para el ejercicio de la potestad de régimen”. Así lo establece, por lo demás, la parte final del c. 129 , \& 1 “... son sujetos hábiles (para el ejercicio de la potestad de régimen)... los sellados por el orden sagrado", mientras que de acuerdo al \& 2 del mismo canon, "En el ejercicio de dicha potestad, los fieles laicos pueden cooperar a tenor del derecho". Es decir que, según las competencias establecidas por el ordenamiento, sólo los ordenados pueden ser titulares del ejercicio de la potestad de régimen, mientras que los laicos, siempre en la medida en que el ordenamiento lo consienta, son sólo llamados a cooperar con tal ejercicio.

En el ordenamiento eclesiástico, a diferencia de los civiles, debido a su especial naturaleza, el gobierno o conducción del "pueblo" hacia su finalidad salvífica, se actualiza en las tres potestades ya citadas: de orden, de magisterio y de régimen, es decir, la denominada "tria munera" del sacerdocio de Cristo, el munus sanctificandi, el munus docendi y el munus regendi. Precisamente, cuando utilizamos la expresión "gobierno" nos estamos refiriendo a la nota distintiva del centro de poder dentro de la organización, esto es su calidad de núcleo de concentración y ejercicio de la potestad o potestades que, por ello, siempre encontrarán una explicación unitaria.

Las tres potestades tienen, en sentido estricto, un carácter eminentemente personal, para cuya comprensión y aceptación jurídica no debemos olvidar la especificidad del derecho canónico, el que no puede separarse ni de los dogmas de fe ni de la ciencia teológica o, especialmente, eclesiológica. Las tres potestades sacras son expresión de un "carisma", en tanto que "gracia" especial conferida por Cristo a sus apóstoles y a los sucesores de estos. Pero esta concesión fue dispuesta por Cristo para ser actuada en el seno de la Iglesia y desde la Iglesia, es decir, de la organización por Él fundada. Por ello, las potestades no 
pueden sino ser ejercidas en las condiciones dispuestas por el ordenamiento, es decir, orden sagrado y misión canónica.

Volviendo al aspecto estrictamente organizativo, la gestión gubernamental propiamente dicha es ejercida en la Iglesia mediante la potestad de régimen, sin perjuicio de que el magisterio es, a la vez que transmisión de la verdad también conducción (se "apacenta" el Pueblo conduciéndolo hacia el Reino); gobierno y magisterio son actuaciones propias, en sentido pleno, de la potestad de orden. Precisamente, como vimos, solo los dotados de potestad de orden, los ordenados, pueden ejercer plenamente aunque según el oficio y órgano de que se trate, la potestad de régimen (cfr. c. 129).

La potestad de régimen, a su vez, es susceptible de especificarse -aunque no, subrayamos, "dividirse" según el esquema funcional que conocemos para las organizaciones políticas- en actividades materialmente de legislación, de jurisdicción (aquí, en el sentido de judiciales) y de administración, cuyo ejercicio se encuentra atribuido a distintos "oficios" según una distinción jerárquica establecida también de acuerdo con criterios de delimitación principalmente personales y territoriales.

Las tres potestades se ejercen según un orden impuesto por el, precisamente, ordenamiento, de una manera que puede asimilarse a la distribución de competencias, aunque más en un sentido jurisdiccional. Es decir, cada oficio ejerce las potestades sacras en una determinada limitación, ya sea material, temporal, geográfica o jerárquica. El Sumo Pontífice concentra la totalidad de las potestades, como también lo hace el Colegio Episcopal con el Pontífice y bajo el Pontífice. El Obispo diocesano lo hace en su diócesis, como también ocurre con las demás Iglesias particulares de acuerdo con el c. $368 \mathrm{y}$, los párrocos, bajo la autoridad del diocesano, en sus parroquias (c. 519) y, realizada la incardinación, también con los presbíteros.

Finalmente cabe señalar que la organización de la Iglesia requiere, como cualquier otra, de una estructura organizativa que cuente, además de los oficios, con órganos de actuación dotados por el ordenamiento de competencias específicas y de un personal a cargo de los 
mismos, ya sea en su dirección y ejercicio de la competencia correspondiente, como en las tareas de apoyo requeridas. Este personal no necesariamente debe pertenecer al "orden clerical" sino también puede estar constituido por laicos. Es decir, la administración material de la Iglesia, su organización administrativa y la gestión administrativa, si bien instrumental con respecto a su misión salvífica, no se confunde, en su naturaleza, con la potestad de orden ni con la potestad magisterial, pero tampoco con la potestad de régimen, siendo meramente auxiliar a las tres.

\section{Recapitulación: oficio, potestad, órgano y competencia}

Podemos intentar una síntesis de los conceptos vistos hasta aquí. El oficio no es un órgano, y tampoco lo reemplaza dentro del complejo organizativo. El órgano es sede de la competencia y como tal es indispensable para la actuación de la organización, pero el oficio es, en sí mismo, ajeno al instituto jurídico de la competencia, sin perjuicio de las aclaraciones que seguidamente veremos.

Aún así, es necesario efectuar algunas precisiones. En el vértice jerárquico de la Iglesia, es decir, el Papa, el Colegio Episcopal con el Papa, cada uno de los obispos en comunión con el Papa, oficio y órgano no son asimilables (es decir, ninguno de los tres puede ser calificado órgano). Los tres son titulares, en plenitud, de las potestades sacras, y así absorben todas las competencias de la organización. Estas son también distribuidas por el ordenamiento en distintos niveles, más inferiores, de la organización, y así, incluso en los oficios clericales, el titular del oficio, por ejemplo el párroco, actúa también como órgano, ejerciendo competencias que son separables de la potestad (especialmente la de orden) que tiene atribuida, mientras que lo mismo, en mayor grado de distinción, ocurre con el presbítero asistente del párroco.

Así entonces, cuanto mayor sea el nivel de la organización, en mayor medida predominará la figura del oficio de manera que aquélla actuará exclusivamente a través de tal figura, la que la sintetiza plenamente: el Papa, v.gr., sintetiza todas las potestades y todas las competencias de la organización. A medida que se desciende en los niveles 
jerárquicos, la figura del oficio se va como desdibujando a favor del órgano. En cierto nivel, convive, como en el caso del párroco, en niveles inferiores -el presbítero, el diácono- y a los efectos de la actividad administrativa, predomina el órgano sobre el oficio. Pero aún así la potestad no desaparecerá: no lo podría hacer ya que es connatural al orden sagrado, aunque de ejercicio en las condiciones establecidas por el ordenamiento.

El oficio es la condición jurídica puesta por el ordenamiento para el ejercicio lícito de las potestades sacras, más precisamente, de la potestad de orden. Esta puede ser ejercida válida o eficazmente por la mera recepción del orden sagrado, aunque no lícitamente, en caso de ausencia de misión canónica (la potestad no tiene la calidad de expedita) para el caso del obispo (salvo en el Colegio Episcopal) o de la incardinación, para el del presbítero, amén de la provisión canónica (o toma de posesión) del oficio en concreto. De esta manera, en ausencia de la misión, el obispo podrá administrar válidamente los sacramentos con sus efectos santificantes propios, pero no lícitamente a los efectos del ordenamiento jurídico. Lo mismo ocurre en el caso del presbítero no incardinado, el que, en tal condición podría, p.ej., administrar válida pero no lícitamente, el sacramento de la eucaristía (cfr. c. 900). Por el contrario, el obispo sin misión canónica (y en principio, sin provisión del oficio) no puede ejercer de ninguna manera la potestad de régimen, de manera que aquí la validez y la licitud se unen. Lo mismo ocurre con la potestad de magisterio, ya que fuera de la comunión con el Papa, las enseñanzas del consagrado (aún el obispo) carecerían de valor moral para los fieles, es decir, no sería parte del magisterio de la Iglesia.

En cambio el órgano solo puede atribuir su actuación a la organización en caso de ajustarse a la competencia -o conjunto de atribuciones jurídicas- que le fue asignada por el ordenamiento. Aquí el concepto, y efectos, de actuación válida y lícita coinciden totalmente. Una actuación fuera del ámbito de la competencia -que tiene que estar expresamente prevista en una norma, o ser resultado de una exigencia no prevista pero necesaria de ella, o ser resultado de una delegación autorizada o avocación no prohibida- será siempre ilícita, o ilegal, 
y por tanto inválida: el acto ilícito es inválido, sancionado por la nulidad, relativa o absoluta, según los casos, por lo que no puede ser atribuido a la organización, aunque sea imputable (p. ej., responsabilidad) a la persona jurídica. Desde esta perspectiva, el órgano puramente administrativo puede ser confiado tanto a un clérigo como, en la medida que no suponga el ejercicio estable de las potestades sacras, a un laico. Este, a cargo del órgano, podrá emitir actos administrativos singulares, en la medida de la competencia asignada y en principio, siempre que no se trate de un rescripto.

En el caso de la potestad de orden, concretamente, el oficio, entonces, habilita al ejercicio lícito de la potestad propia del ordenado -potestad que pertenece al ordenado, no al oficio, esta es la condición puesta por el ordenamiento para su ejercicio lícito- mientras el órgano debe ajustarse a su competencia para actuar válida y lícitamente. En cambio, en los casos de las potestades de régimen y de magisterio, si bien la potestad requiere como presupuesto esencial la previa recepción del sacramento del orden, sólo puede ejercerse en posesión válida del oficio. Así para estas otras dos potestades, el orden será también un presupuesto, pero la válida posesión de oficio será una suerte de condición suspensiva: existe el "derecho" (deriva del orden) pero no es eficaz y de lícito ejercicio fuera de la misión o la incardinación.

Lo cierto es que la potestad es el mismo poder del ordenamiento, que en el canónico o eclesiástico se encuentra absolutamente centralizado en el Romano Pontífice y en el Colegio Episcopal con aquél, mientras que, en la actualidad en la gran mayoría de los ordenamientos civiles, se encuentra descentralizado en los tres "poderes" del Estado, de tal manera que podría decirse que en estos ordenamientos el poder ha sido otorgado por las constituciones (por el pueblo constituyente) al Estado, a través de tres órganos supremos, mientras que en la Iglesia el poder ha sido dado por el Supremo Legislador al oficio pontificio. 


\section{Las tres concepciones de oficio en el derecho canónico}

Como hemos visto, en el ordenamiento canónico no sólo no se encuentran expresamente diferenciadas entre sí las figuras de órgano y de oficio, sino que esta última tampoco es utilizada en un sentido unívoco.

Pero del mismo sistema del CIC es posible, creo yo, distinguir tres concepciones de la figura de oficio: a) genérica; b) estricta y c) estricta y restringida.

La primera es la que resulta del c. 145 \& 1: oficio es todo munus que se deba ejercer para un fin directamente espiritual. Desde esta perspectiva, oficio es la condición organizativa para el ejercicio de las potestades sacras, pero también, cuando se trata del ejercicio de la potestad de régimen, la sede de las competencias para ejercer las actividades materialmente legislativas, judiciales o administrativas. Aquí las figuras de oficio y órgano tienden a confundirse, y, en ciertas condiciones, pueden ser ejercidos por laicos. En sentido genérico también toda la organización ejercita un oficio, el pastoral y sacramental, incluso considerado como conjunto de derechos y deberes, como lo afirma el c. 232 con respecto al derecho y deber propio y exclusivo de la Iglesia de formar a aquellos que se destinan a los ministerios sagrados; "Ecclesiae officium est..." dice la versión latina de la norma citada.

$\mathrm{Si}$ en sentido genérico oficio es todo munus, en sentido estricto es la condición de ejercicio de las potestades sacras, lo que se apoya fundamentalmente en el derecho divino, pero también en el derecho puramente eclesiástico, que lo regula y lo concretiza.

Pero todavía es posible aislar un sentido estricto y restringido de oficio, limitado al ejercicio de la potestad de régimen en sus tres actividades. Esto es gobierno, y pertenece al orden sagrado, sin perjuicio de que ciertas competencias puedan ser ejercidas por laicos a cargo de órganos creados y delimitados por el derecho eclesiástico. Aún así debemos recordar, con el Papa Francisco (EA, 104), con cita de Juan Pablo II, que "cuando hablamos de la potestad sacerdotal "nos encontramos en el ámbito de la función (creo que lo dice en el sentido de oficio) no de la dignidad ni de la santidad", ya que, continúa, la "gran dignidad viene del Bautismo, que es accesible a todos". Y advierte "Aún cuando 
la función del sacerdocio ministerial se considere 'jerárquica', hay que tener bien presente que 'está ordenada totalmente a la santidad de los miembros del Cuerpo Místico de Cristo'. "Su clave y su eje -agregano son el poder entendido como dominio, sino la potestad de administrar el sacramento de la Eucaristía...".

En definitiva, recuerda la EG, 102, "Los laicos son simplemente la inmensa mayoría del Pueblo de Dios. A su servicio está la inmensa minoría de los ministros ordenados". Me permito cerrar esta exposición, en una suerte de glosa de la EG (con todo respeto) diciendo que el oficio ejerce la potestas, que regulan las normas de derecho divino y de derecho eclesiástico, sólo en cuanto es munus, servicio al Pueblo de Dios.

\section{The authority, office and competence in the canonical legal system}

The publication take the law of the Church as its subject. It consists of eight parts. In the first one, the author presents the Church from a legal and organizational perspective. In particular, he draws the attention to the institutional dimension of the People of God. The second part is devoted to the reflections on the legal system that exists in the Church. Continuing his arguments, the author turns to the present - in the third point the organization of the Church and offices associated with Her. Then, in the fourth and fifth parts there are included arguments of such concepts as: the authority (el órgano), the office (el oficio), the duty and obligation (el cargo), the task (el munus), the function (el ministerio), the task (el oficio). In the sixth part he divagates on the authority of teaching, sanctifying and governing. In the next, the seventh part, the author attempts to a synthetic presentation of the reality of the office, authority and competence of the Church. The last, eighth part is dedicated to the three ways of understanding of the concept of office (el oficio) in the Canon Law.

\section{Bibliografía}

Ariño Ortiz Gaspar, La administración institucional. Bases de su régimen jurídico. Mito y realidad de las personas jurídicas en el Estado, Instituto de Estudios Administrativos, Madrid, 1972.

Barra Rodolfo C., Tratado de derecho administrativo, Tomo 1, Ábaco, Buenos Aires, 2002. 
Berti GIORgIO, La pubblica amministrazione come organizzazione, CEDAM, Padova, 1968.

CARdia Carlos, Il governo della Chiesa, Il Mulino, Bologna, 1993.

Código de Derecho Canónico (CIC), Biblioteca de Autores Cristianos (BAC), Madrid, 1989.

Codice di Diritto Canonico e leggi complementari, Coletti a San Pietro edit., Roma, 2007.

Giannini Massimo S., Diritto amministrativo, Vol. I, Giuffrè, Milano, 1993.

Giannini Massimo S., Istituzioni di diritto amministrativo, 2da. Edición, Giuffre, Milano, 2000.

Hervada JaVIer, Diritto costituzionale canonico, Giuffrè, Milano, 1989.

Labandeira Eduardo, Trattato di diritto amministrativo canonico, Giuffre, Milano, 1994 - versión italiana de la original edición castellana, Tratado de Derecho Administrativo Canónico, EUNSA, Pamplona, 1993.

Mörsdorf Klaus, Fondamenti del diritto canonico, Marcianum, Venecia, 2008.

Pinto P. V., Diritto amministrativo canonico, EDB, Bologna, 2006.

S.S. Benedicto XVI, Encíclica Caritas in veritate.

S.S. JuAn Pablo II, Exhortación Apostólica Pastores gregis.

S.S. JuAn XXIII, Encíclica Pacem in terris.

S.S. Francisco, Exhortación Apostólica Evangelii Gaudium. 